Caligrama, Belo Horizonte, v. 24, n. 1, p. 111-126, 2019

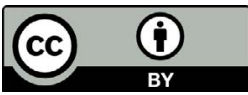

\title{
Endereçamento e epistolaridade: poesia e circunstância em Mallarmé
}

\author{
Addressing and Epistolarity: \\ Poetry and Circumstance in Mallarmé
}

\author{
Sandra Mara Stroparo \\ Universidade Federal do Paraná (UFPR), Curitiba, Paraná / Brasil \\ smstroparo@gmail.com
}

Resumo: Este trabalho procura pensar a questão do endereçamento epistolar em Mallarmé, unindo essa possibilidade à questão do endereçamento poético. Questões como quem escreve e para quem, são problematizadas para repetir o que parece ter sido o próprio processo do autor francês, seja nas suas cartas (e envelopes), seja na sua poesia (incluindo a de circunstância), seja na sua ensaística. As quadrinhas de Les Loisirs de la Poste são tomadas como exemplo lúdico de uma experimentação autoral, ao mesmo tempo que de uma procura por um leitor ideal, capaz de ler um endereço oficial a partir delas. Essas quadras são reveladoras de uma reflexão mais ampla do autor que, em uma experiência epistolar, pode testar a noção de identidade pessoal e autoral até o ponto da despersonalização, noção fundamental para a modernidade.

Palavras-chave: cartas; identidade; despersonalização; Mallarmé.

\begin{abstract}
This paper aims to study the addressing of letters in Mallarmé, along with the problem of poetic addressing. Who writes, and to whom, are questions considered here in order to repeat what seems to have been the french author's project, in his letters (and envelopes), poetry (including the one of circumstance), and in his essays. The quatrains in Les Loisirs de la Poste are considered as a playful example of authorial experimentation as well as the search for an ideal reader, capable of reading them as an official address. These quatrains reveal a wider reflexion of an author who, in an epistolary experience, can sound the notions of personal and authorial identity, stretching them to the point of depersonalization, a fundamental notion for the modern condition.
\end{abstract}

Keywords: letters; identity; depersonalization; Mallarmé. 
Quem escreve? Para quem? E para enviar, destinar, expedir o quê? Para que endereço? Sem nenhum desejo de surpreender, e assim de chamar atenção às custas de obscuridade, devo dizer ao que me resta de honestidade que finalmente eu não sei.

(DERRIDA, La carte postale.)

Quando alguém escreve uma carta, para quem escreve? Para o destinatário registrado no envelope?

Leur rire avec la même gamme

Sonnera si tu te rendis

Chex Monsieur Whistler et Madame,

Rue antique du Bac 110.

(MALLARMÉ, 1998, p. 241, tradução minha.) ${ }^{1}$

Para aquele Outro (considere-se o $O$ lacaniano) que existe em outro lugar, senão, longe demais ao menos, momentaneamente fora de alcance? Em que sentido, fora de alcance? Não é isso que a carta permite? comunicar, informar, aproximar? Se é isso que se espera, se é isso que a carta permite, se é isso que se pode considerar quando se escreve uma carta, quando se recebe uma carta, o que é que se recebe? O que de fato se percebe?

Par la bise transi, pauvre homme

Ou si tu les connais, charmé

Rue, au 89, de Rome

Va chez Mesdames Mallarmé.

(MALLARMÉ, 1998, p. 263, tradução minha.)²

O autor de uma carta interpela ${ }^{3}$ seu destinatário? Incomoda? O autor de uma carta surpreende, lisonjeia? Quem recebe uma carta, quer recebê-la? Se quer, a carta realiza seu desejo? Se não quer, o que é a carta? Uma carta, um enfado, um logro, uma bomba?

${ }^{1}$ Seus risos no mesmo tom/ Soarão, se fores/ À casa do Senhor Whistler e Senhora,/ Rua antiga do Bac 110.

${ }^{2}$ Pelo vento gelado, pobre homem/ Ou se as conheces, encantado / Rua, no 89, de Roma/ Vai à casa das Senhoras Mallarmé.

${ }^{3} \mathrm{Ou}$, como quer Derrida, "apostrofa"?: C'est ainsi un genre qu'on peut se donner, l'apostrophe... In: La carte postale, p. 8. 
Je te lance mon pied vers l'aine

Facteur, si tu ne vas où c'est

Que rêve mon ami Verlaine

Ru'Didot, Hôpital Broussais.

(MALLARMÉ, 1998, p. 264, tradução minha.) ${ }^{4}$

A quem pertence uma carta? No momento em que a escreve, ao autor. Quando a recebe, ao destinatário. Entre um e outro, ao carteiro. Qual é a natureza real desse objeto de propriedade volúvel? O texto que apresenta o discurso, apenas o assunto ou a ideia que carrega, ou trata-se de tudo: papel, tinta e discurso?

\section{Madame Madier qu'on fréquente \\ Trop peu. Lettre, vole jusqu'où \\ Brille le numéro cinquante \\ Rue, ô delices, de Moscou!}

(MALLARMÉ, 1998, p. 267, tradução minha) ${ }^{5}$

As cartas fazem perguntas, mas apresentam também algumas respostas. Assim parece, ou, ao menos assim o grande conjunto das cartas de Stéphane Mallarmé nos faz acreditar. As cartas de Mallarmé são objeto de estudo e suporte para o estudo de sua obra desde a década de 1940 do século XX, quando começaram a ser publicadas (por Henri Mondor). A partir de 1959, até 1985, elas foram publicadas em uma coleção de onze volumes (que já recebeu mais um irmão menor, em 1998), e definiram radicalmente a leitura de sua biografia e de seus poemas, além de dar a ver uma perspectiva absolutamente moderna de construção da identidade literária do eu poético, propriamente dito. A verdade é que nas cartas algumas das ideias que forjaram a obra estão, embora dispersas, expostas de maneira a oferecer um caminho de investigação para a voz que possibilitou, direta ou indiretamente, a criação de poemas como Un coup de dés e tudo que ele poderia oferecer, não só como novidade formal, mas também como a pretensão a uma criação absoluta (grande desejo de Mallarmé, ensaiado nesse poema e projetado para Le Livre).

\footnotetext{
${ }^{4}$ Arremesso meu pé em tua virilha,/ Carteiro, se não fores ao lugar/ Em que sonha meu amigo Verlaine/ Rua Didot, Hospital Broussais.

${ }^{5}$ Madame Madier que frequentamos/ tão pouco. Carta, voa até onde/ Brilha o número cinquenta/ Rua, oh delícias, de Moscou! La carte postale, p. 267.
} 
Assim, entre as construções de um eu epistolar, a realidade de sua obra poética, e seus interlocutores, Mallarmé construiu em suas cartas, às vezes, à revelia de si próprio e de seus destinatários, uma bela parcela do discurso da modernidade. O homem desse meio e desse momento alguns o chamam de atormentado e dividido - precisa descobrir qual é o sentido que construirá dali para frente. Esse homem é vários, mas poucos, e é Outro (ao menos desde Rimbaud). Mallarmé é esse outro e, Outro, um desses vários, um desses poucos.

Os quartetos citados acima são alguns exemplos das 63 quadrinhas a que temos acesso hoje. Mallarmé separou (e provavelmente reescreveu algumas delas) 27 dessas quadrinhas sob o título de Loisirs de la poste. Alguns anos depois de sua morte, sua filha e seu genro publicaram as Récreations postales, autres quatrains, com um conjunto maior. Considerados o exemplo mais acabado de sua poesia de circunstância, esses quartetos não faziam exatamente parte das cartas, mas eram escritos no próprio envelope, substituindo a formal apresentação do destinatário. Mallarmé afirma em seu prefácio aos Loisirs de la poste, escrevendo em "honra ao Correio" (1998, p. 241), que nenhum desses endereçamentos deixou de alcançar seu destino.

Em um autor reconhecido como difícil, com uma obra que se distancia do (e distancia o) leitor, essas quadrinhas aparecem como um alento de afabilidade e graça, como cabe à poesia de circunstância.

A crítica de Mallarmé já insistiu bastante no fato de que toda sua obra seria circunstancial - é interessante lembrar que Manuel Bandeira já houvera percebido isso (BANDEIRA, 1997, p. 166) -, considerando as exceções de Igitur e Un coup de dés e, claro, do "Livre".

Na realidade, Mallarmé escreveu quase toda sua obra a partir de circunstâncias. [...] À medida que Mallarmé publicava, e mais e mais depois de sua morte, sucedia a sua obra esta desventura, ou esta transfiguração: ela se tornava literatura. O poema escrito sobre um leque é um presente para uma amiga, depois se torna página de um livro que os críticos estudam. Mas para o autor esses textos eram apenas cacos, cartões de visita... (SCHERER, 1977, p. 17, tradução minha. $)^{6}$

\footnotetext{
${ }^{6}$ É importante comentar aqui que a aproximação de alguns poemas publicados a "cacos e cartões de visita" foi feita pelo próprio Mallarmé em uma carta a Verlaine, de 16 nov. 1885 .
} 
Mas essa "circunstancialidade" não é uma conclusão unânime. Inclusive, pelo fato de Mallarmé ter reescrito, inúmeras vezes, quase todos os seus poemas, que mesmo tendo surgido como poemas de circunstância acabaram se transformando em literatura, mas por força e obra do próprio autor, e não por uma mera mudança de estatuto devido a sua descoberta e publicação.

Um bom exemplo de estudo desse processo constante de criação e recriação de Mallarmé, está no trabalho de Paul Bénichou, Selon Mallarmé. A leitura de alguns poemas escolhidos é feita a partir de várias leituras de estados anteriores do mesmo poema, publicados em veículos diferentes com espaços de tempo, às vezes, bastante consideráveis. ${ }^{7}$ Ao analisar o processo de reescrita do poema, o crítico joga luzes sobre a versão final, frequentemente, mais refratária a uma primeira leitura. ${ }^{8}$

De qualquer modo, os quartetos fazem hoje parte das obras completas, mas não estão presentes em todos os volumes da Correspondance do autor (a edição de suplementos às cartas, de 1998, traz mais alguns deles). Essa separação evidencia uma interessante distinção de gênero, decidida pela crítica: carta é carta, envelope é envelope, poema é poema, mesmo se foram escritos e enviados fisicamente juntos.

Mas essas quadras, escritas em envelopes, aproximam a obra da correspondência e, é inevitável, as equiparam. Quem escreve a quadra e quem escreve a carta? A quadra é do autor, e, portanto, do autor moderno preocupado com o distanciamento autor-texto, defendendo o "desaparecimento elocutório do poeta" (MALLARMÉ, 2010, p. 164), ou é de Stéphane Mallarmé, o sujeito biográfico que assina a carta dentro do envelope?

Todas essas perguntas se fazem importantes por si sós, na medida em que problematizam alguns dos aspectos importantes, seja para os estudos da epistolaridade, seja para a poesia de circunstância do autor.

\footnotetext{
${ }^{7}$ Consideradas como muito importantes, essas versões estão todas disponíveis na edição das Oeuvres Complètes de 1998 e 2003.

${ }^{8} \mathrm{Se}$ escolhermos ser extremamente preciosistas, veremos que esse processo soa como uma pequena trapaça da crítica, que de posse de várias versões pode analisar com mais facilidade a versão final e, claro, mesmo a inicial, já que o processo de reescritura do autor sempre se deu de forma a tornar o texto menos preciso, mais sucinto, menos objetivo e, no limite, menos claro. No entanto, como o próprio Mallarmé disponibilizou todas essas versões, não se trata de crítica genética, e a fortuna crítica sobre sua obra construiu-se, desde o início, dessa maneira.
} 
E elas também podem revelar, aos poucos, questões relacionadas à obra de Mallarmé como um todo, num caminho de duas mãos entre seus discursos literário, ensaístico e ficcional.

Isso nos leva a um ponto comum a praticamente toda a crítica sobre o autor. Mallarmé escreveu muitos textos de naturezas muito diversas, num trânsito bastante peculiar entre gêneros, e a crítica pôde se alimentar - como em um buffet gourmet - de alguma prosa poética coerente com as Letras pós-Baudelaire (ou pós Aloysius Bertrand e seu Gaspard de la Nuit, como alegavam Mallarmé e o próprio Baudelaire); de escolhas tradutórias que indicam generosamente suas influências; de várias versões, publicadas, de um mesmo poema, que revelavam a evolução de seu pensamento poético; bem como de uma rica variedade de ensaios, por exemplo, auxiliam a leitura desses mesmos poemas, enquanto explicitam certas perspectivas estéticas definidoras. A partir de 1959, então, quando sua correspondência passou a ser publicada, essa diversidade de discursos foi acrescida de uma - outra? - voz, que revelava ainda mais sobre o conjunto desses textos.

Essa variedade, no entanto, também implicou um certo descaso pelas diferenças. As leituras cruzadas se multiplicam e se auxiliam, mas se a própria diferença - uma carta e um ensaio, por exemplo - for uma interrogação, ou se a identidade e particularidade de certos textos for um tema de discussão, vemos que a fortuna crítica do autor oferecerá, proporcionalmente, poucos estudos.

Muitas vezes Mallarmé foi lido na perspectiva de uma escrita "generalizante", situada além das distinções tradicionais, e que representa o modelo por excelência de uma prática literária "moderna", em que o gênero jamais é convocado em função de seu valor contratual, mas unicamente em vista de sua própria subversão. [...] É incontestável que com Mallarmé a questão dos gêneros se desloca, que certas distinções, como por exemplo entre prosa e poesia, ou entre teoria e ficção, se tornam problemáticas, e podemos então preferir a hipótese de uma escrita genérica, de um trabalho diretamente sobre a linguagem. (KAUFMANN, 1986, p. 20-21, tradução minha.)

Mas se tentarmos resgatar alguma distinção entre os textos, talvez possamos nos aproximar, por exemplo, de suas cartas com um pouco mais de segurança, tentando partir de algumas questões que vão além do tema ou de algumas características mais formais de organização e 
apresentação do texto. Uma abordagem dessa possibilidade, ainda que em seus textos mais facilmente considerados "poéticos", é o que procura discutir Le livre et ses adresses, de Vincent Kaufmann. A partir de algumas dúvidas quanto ao lugar e a importância do leitor que a teoria da recepção vinha propondo (o livro é de 1986), o crítico considera que a "função interlocutória" reconhecida faz com que a crítica às vezes estabeleça um "diálogo de surdos" entre o leitor ideal e o implícito (e ainda, no limite, o autor), defendendo que se essa relação existe, ela se deve, sobretudo, ao próprio texto e suas estratégias particulares, únicas para cada texto, e que é preciso reconhecer ao menos algum tipo de "precedência" ao autor. $\mathrm{Na}$ "estratégia discursiva" elaborada por ele estariam, então, segundo Kaufmann, os dispositifs d'adresse, ("dispositivos de endereçamento"), ${ }^{9}$ que revelariam a capacidade do texto de representar sua própria "regra de destinação" e seriam no limite, também reveladores de mecanismos de gênero, como singularizadores da "ficção contratual".

$\mathrm{O}$ endereçamento do texto seria o conjunto dos procedimentos pelos quais ele dá forma à ligação que propõe e em certa medida impõe ao leitor. Em referência à noção de ordem simbólica desenvolvida pela antropologia estrutural, e depois pela psicanálise lacaniana, eu diria ainda sobre o texto que ele constitui um dispositivo simbólico autônomo, que ele institui uma ficção contratual singular, agindo diretamente sobre a língua. (KAUFMANN, 1986, p. 8-9, tradução minha.)

Para deixar um pouco mais claro, Lacan derivou o conceito de ordem simbólica dos estudos de Lévi-Strauss, e estendeu-o até o nó borromeano, ou nó Borromeu, mostrando-o imbricado com a ordem real e a imaginária. Na ordem simbólica, estão os contratos de convívio e relação, os aspectos culturais que os definem aquilo que, na teoria do sujeito, trata do que é "público". ${ }^{10}$

A questão levantada por Kaufmann é que se podemos reconhecer que a obra possui de fato um dispositivo de endereçamento, há um papel

\footnotetext{
${ }^{9}$ Vale aqui uma rápida exposição do termo: adresse, endereço, destino, endereçamento. ${ }^{10}$ Tenho perfeita consciência do grau de limitação e imprecisão que um parágrafo apenas sobre esse assunto oferece a um tema tão importante como a definição da ordem simbólica e a teoria do sujeito, de Lacan. Considero, apenas, que a noção da ordem simbólica, necessária aqui mas limitadamente, não pede para este trabalho uma especulação mais extensa.
} 
duplo possível para o leitor, mais fértil que os anteriormente cogitados: o leitor é o destinatário, mas é também o "terceiro" capaz de compreender e analisar esse endereçamento.

Não precisamos olhar para essa proposta apenas como uma alternativa aos papéis de leitor implícito, ideal ou empírico, ou como novos nomes para os mesmos conceitos, porque os endereçamentos estariam profundamente ligados à natureza mais particular de cada obra: cada uma delas apresentaria sua relação específica com o Outro ${ }^{11}$ e seus próprios dispositivos de endereçamento, desvelados à medida que nos aproximamos de certos detalhes e especificidades, fazendo, na verdade, com que cada leitor, ao descobri-los, se descubra igualmente a "fonte e o efeito" desse dispositivo. O endereçamento, premissa do autor, estabeleceria, portanto, a "simbolicidade literária", a Symbolicité littéraire.

Monsieur Monet, que l'hiver ni

L'été, sa vision ne leurre,

Habite, en peignant, Giverny

Sis auprès de Vernon, dans l'Eure.

(MALLARMÉ, 1998, p. 241, tradução minha) ${ }^{12}$

Se retornamos, portanto, a Les Loisirs de la poste, podemos ver - num processo divertidamente redundante - a possibilidade do endereçamento que se realiza como que entre espelhos, multiplicando indefinidamente as imagens: o endereço para o carteiro, que é o endereço de Monet, pelo carteiro é lido para que a carta chegue até o pintor, que, graças ao contrato estabelecido entre Mallarmé e o correio, seguindo os termos do endereço, digo, do poema, pode finalmente abrir e ler a carta. Mallarmé escreve ao carteiro, o leitor a quem o "dispositivo de endereçamento" do poema é dirigido, e seja como poema, seja como termo de contrato, ele se realiza. Em outros termos, o carteiro é o leitor empírico e o ideal, já que a carta alcançou seu destinatário.

Mas Mallarmé, como sempre, levou tudo ainda além.

${ }^{11}$ O Outro lacaniano. Considerar Lacan, 1979, cap. IV.

${ }^{12}$ Senhor Monet, que inverno/ Ou verão, sua visão não ilude,/ Mora, pintando, em Giverny/ Situada perto de Vernon, no Eure. 
Monsieur Mallarmé. Le pervers

À nous fuir, par le bois, s'acharne;

Ô Poste, suis sa trace vers

Valvins, par Avon Seine-et-Marne.

(MALLARMÉ, 1998, p. 273, tradução minha.) ${ }^{13}$

Mallarmé escrevendo para si mesmo? Independente da possibilidade de o envelope estar ou não vazio, o jogo de espelhos aqui alcança ainda uma outra, e mais importante, constatação. Ao enviar as quadras a destinatários diferentes o processo se cumpria, mas longe de seus olhos. Recebendo, ele mesmo, um desses envelopes, ele atesta a garantia e, especialmente, a confirmação do poema, como poema e como parte do contrato: o dispositivo simbólico é testado e validado.

"O poema-endereço sublinha a necessidade de dar um estatuto simbólico (público) ao que, sem passagem por um terceiro, não existiria de todo." (KAUFMANN, 1986, p.33) E aqui, repetindo a crítica, vale a pena perseguir algumas "explicações" do próprio poeta/ensaísta.

Em “L'Action restreinte", um ensaio importante de Divagations, publicado originalmente na Revue Blanche, em 1895, Mallarmé oferece uma chave possível para esse jogo de endereçamentos. Como disse Fernando Scheibe, tradutor de Divagações no Brasil, esse é um livro que trata das "possibilidades políticas da poesia" (SCHEIBE. In: MALLARMÉ, 2010, p. 10) e esse texto, particularmente, fala da "ação" do autor.

O escritor, de seus males, dragões que ele mimou, ou de uma alegria, deve se instituir, no texto, o espiritual histrião.

[...]

Publique.

O Livro, onde vive o espírito satisfeito, em caso de mal-entendido, um obrigado por alguma pureza de folguedo a sacudir o grosso do momento. Despersonificado, o volume, tanto quanto a gente se separa dele como o autor, não reclama aproximação de leitor. Tal, saiba, entre os acessórios humanos, ele tem lugar totalmente só: feito, sendo. O sentido sepultado se move e dispõe, em coro, das folhas. (MALLARMÉ, 2010, p. 171-173)

\footnotetext{
13 “Senhor Mallarmé. O perverso/ Que nos foge, pelos bosques, obstinado;/ Oh Correio, siga seu rastro por/ Valvins, por Avon Seine-et-Marne." O poeta passava suas férias às margens do Sena, em Valvins, commune de Avon, no departamento Seine-et-Marne.
} 
Há mesmo imperativos em alguns parágrafos, o que é especialmente interessante para o verbo "publicar": depois de anos com um projeto de "Obra" pronto (ao menos desde 1867, segundo ele informou a mais de um de seus correspondentes), Mallarmé tinha ainda publicado muito pouco, causando por isso reações variadas de admiração pelo suposto mistério, mas também, às vezes, reações estranhas como a de Max Nordau (1892), que o considerava alguém incapacitado.

Nesse texto, no entanto, há uma aparente contradição. Ele, quase sem publicações, fala do "ser escritor", e é incisivo, acrescentando um "Publique". Mas, afirma que o livro, impersonnifié, "não reclama aproximação de leitor". Essa sentença já foi usada de várias maneiras pela crítica, inclusive como prova de acusação, concluindo que o suposto descaso do autor pelo leitor justificaria o hermetismo atribuído a sua obra. Mas talvez não seja só isso, ou não seja tão simples assim.

Enquanto em algumas obras a estratégia discursiva, a do endereçamento, pode ser relativamente explícita, o extremo oposto, sua negação, a aparente recusa, uma espécie de "silêncio de endereçamento", acaba por se tornar uma estratégia discursiva equivalente, como que a confirmar o fato de que nenhum texto "saberia conceber-se sem a inscrição de seu endereçamento" (KAUFMANN, 1986, p.10).

$\mathrm{O}$ uso desse conceito por Kaufmann é coerente com o que ele propõe para a leitura de alguns textos - Mallarmé, Valéry, Ponge e Blanchot. $\mathrm{O}$ crítico, na realidade, os apresenta como responsáveis pelo levantamento de suas hipóteses, considerando-os como pertencentes a uma mesma linhagem moderna de autores cuja linguagem poética, deliberadamente, recusou o diálogo com o leitor, ao menos em sua forma patente. E Mallarmé é, historicamente, o primeiro deles.

Mallarmé foi considerado o campeão da intransitividade, o modelo de todas as modernidades, o padroeiro da autoreflexividade e o náufrago mais glorioso entre os exploradores da face negra da linguagem. Sem dúvida era demais podermos esperar das teorias da recepção que considerassem seu caso com um pouco de serenidade. E de fato, elas ficam, frequentemente, no mínimo embaraçadas quando não buscam torná-lo responsável (e em seguida aqueles que se inscrevem de uma maneira ou outra em sua filiação) por uma crise ou uma destruição da literatura pretensamente ligada à exclusão do leitor. O que é igualmente paradoxal: raros são de fato os escritores que procuraram 
representar, expor com tanta radicalidade e constância qual seria o lugar do leitor em relação à escrita. Com Mallarmé, os investimentos simbólicos do discurso literário passam ao primeiro plano, em um tipo de projeto ou de síntese. Em uma época em que, nas ruínas da glória romântica, as legitimações da escrita devem ser repensadas, sua força está sem dúvida em ter colocado a questão da autoridade da escrita como tal, o que dá a seu gesto uma dimensão teórica até aqui muito pouco analisada. (KAUFMANN, 1986, p.11, tradução minha.)

Mas, como vemos, é possível também encarar essa postura por um outro viés. Não era aparentemente só a obra de Mallarmé que estava planejada por ele, mas o modo - e os significados - de fazê-la, também. A premissa, a "precedência do autor" a que Kaufmann se refere e que, afirma, encontrou como hipótese inicial em alguns autores do século $\mathrm{XX}$, parece justamente compor a ciência desse projeto.

A conclusão sobre a "autoridade da escrita" no texto de Kaufmann é uma análise contemporânea, uma conclusão post facto de uma elaboração que custou a Mallarmé anos de preparo, e que talvez ele não colocasse nesses termos, objetivos e incisivos demais para a veia poética sinuosa que ele mantinha, mesmo em sua ensaística.

Voltando à citação de "L'action restreinte", vemos que a imagem do "histrião" - o bufão, o farsista - parece equivaler à descrição do autor cabotino, tão cara aos estudos modernistas. Ao assumir o cabotinismo, Mallarmé, contudo, lhe concede efetivamente mais independência e, no limite, autoridade sobre o que quer que "diga", precisamente graças ao distanciamento em relação à figura do autor. A despersonificação do texto é o afastamento, distanciamento texto/autor, daquele autor que ele era na "ruína" de uma era, a do "eu profundo" dos românticos. E na realidade a palavra "afastamento" explica apenas timidamente a radicalidade da despersonalização apresentada na obra de Mallarmé. A autoridade é, portanto, da escrita.

Nosso Modernismo pode nos oferecer um paralelo interessante: ao tratar da "língua" brasileira de Mário de Andrade, Anatol Rosenfeld diz que ele "certamente prejudicou muitas vezes a obra pelos excessos do 'seu' idioma", mas eles faziam parte não só da atitude do momento, como também do pensamento de Mário sobre sua literatura, e sua busca por "sinceridade" e espontaneidade. Para Mário, a língua "pronta", petrificada, não permitiria que "a paisagem do [meu] eu profundo" 
(ANDRADE, 1987, p. 59-77) viesse à tona. Ao poeta caberia inventar uma outra língua:

Usando essa língua "alienada", falsificamos as nossas vivências autênticas. Ela se torna máscara rígida, borrando nossa verdadeira identidade; é mera aparência, forma fixa que não corresponde à vida fluida. O problema é universal. Não será a língua sempre algo exterior à nossa paisagem profunda? Essa questão - que implica a do cabotino - veio a ser um dos temas fundamentais a partir dos grandes "desmascaradores" Schopenhauer, Nietzsche e Freud. De uma outra forma derivam daí alguns dos temas centrais de autores como Pirandello, Thomas Mann, Fernando Pessoa, Ionesco. Mas já Schiller dissera: "Quando a alma fala, já não fala a alma." O dom mais alto do homem transforma-o ao mesmo tempo em cabotino. Omnis homo mendax [Todo homem é mentiroso]. (ROSENFELD, 1996, p.188)

Rosenfeld, portanto, problematiza a postura de Mário e mostra aos poucos como a literatura lida com várias tensões: entre a "vontade da sinceridade" e sua representação; entre a subjetividade autoral, a paisagem do "eu profundo", e sua projeção para a coletividade. Ainda que esta invenção se dê de boa-fé, buscando uma espontaneidade supostamente existente, quanto mais "inventada", mais artifício essa língua representa: "nega a sinceridade e faz duvidar da própria sinceridade da sinceridade." (ROSENFELD, 1996, p.189)

Mallarmé, em seu tempo, também foi acusado de alienação. Aliás, de diversos tipos diferentes de alienação: da política à psicológica. Mas, se aceitamos o texto de "L'action restreinte", percebemos que ele criou - e manteve - uma língua alienada em sua obra, mas com plena consciência e domínio disso. Mallarmé não negava a existência de sua "paisagem interior", e aliás, falou bastante dela em algumas de suas cartas, mas o que ele não queria era confundir o "Ideal com o Real" (MALLARMÉ, 1959, p. 90, tradução minha. $)^{14}$, e arbitrária e deliberadamente, transformou essa paisagem em uma literatura impessoal.

Rosenfeld também afirmou sobre Mário de Andrade, considerando versos como o "eu sou trezentos": "manifesta-se uma consciência aguda, às vezes desesperada, da multiplicidade mesclada do próprio ser, mas ao mesmo tempo o sentimento transbordante da riqueza daí decorrente"

\footnotetext{
${ }^{14}$ Em carta a Cazalis, 3 jun. 1863.
} 
(ROSENFELD, 1996, p. 191) Mário precisou lidar com a multiplicidade que sua visão de mundo demandava para a literatura, precisava resolver o vário em si para achar sua voz. Mallarmé não está preocupado com o "plural", mas sua singularidade também não é estrita e estreitamente sua, na medida em que o "eu" da obra que produziu é outro, é o Outro: o imaginário resolve-se no simbólico.

Isso tudo dependeu de uma violentíssima racionalização, resultado de um processo sensível, a que o poeta chegou, a partir de uma descida aos infernos mais pessoais de suas capacidades individuais e criativas, através da descoberta do que ele chamou de Nada: "a destruição foi minha Beatriz" (MALLARMÉ, 1959, p.246, tradução minha.) ${ }^{15}$.

Assim, em "L'Action restreinte", o trecho supostamente contraditório leva a despersonalização a outro extremo: "Despersonificado, o volume, tanto quanto a gente se separa dele como autor, não reclama aproximação de leitor." Publique, mas não espere leitor? Despersonifiquem-se, autor e leitor? A desaparição do leitor ainda justificaria a existência da obra? Sem buscar uma resposta exata a essas questões, podemos voltar ao quarteto que Mallarmé endereçou a si mesmo e perceber que ele é, de certa forma, a concretização desse posicionamento literário.

Mallarmé parece saber, e tentar provar, que a verdadeira existência do texto depende de sua entrada na ordem simbólica, a qual se dá, para um texto literário, através do processo de publicação. A partir desse momento, o texto passa a existir, independente da voz e da mão do autor e, em seu outro - ou no mesmo? - extremo, independente do fato de ser ou não lido. $\mathrm{O}$ dispositivo de endereçamento existe, mesmo se acompanhado da negação da necessidade de um leitor: o poeta histrião registra sua performance - mesmo se a plateia estiver vazia.

Mallarmé cumpriu uma longa trajetória criativa para chegar a "L'Action restreinte", o que significa que suas descobertas foram

\footnotetext{
${ }^{15}$ Em carta a Eugène Lefébure, 17 mai. 1867. Sobre o período que levou Mallarmé a essa descoberta, muito já se escreveu. Profundamente ligado ao momento de afastamento do autor dos amigos e da vida cultural de Paris, resultado de seu emprego como professor de liceu no interior francês, esse período de verdadeira depressão psicológica e criativa foi uma espécie de germinação da maioria das grandes ideias e projetos de obra do autor. Da sua "descoberta do Nada", Mallarmé chegou por exemplo a sua perspectiva de despersonalização do sujeito poético, tão importante para a poesia moderna. Ver também Friedrich (1991, p. 95-140).
} 
graduais, passaram da reflexão à obra e da obra ao ensaio. O acesso que se tem hoje a toda sua poesia e ensaística, bem como toda a fortuna crítica gerada a partir delas, facilita nossa própria percepção dessa trajetória, não necessariamente simplificando-a, mas permitindo que se chegue direto a conclusões importantes que custaram ao autor toda uma vida de trabalho. Para perceber melhor esse caminho, podemos resgatar algumas etapas dessa trajetória através, por exemplo, da leitura das várias versões de seus poemas e de seus ensaios, e certamente através de algumas de suas cartas.

Repetindo a afirmação de Kaufmann citada há algumas páginas, "com Mallarmé, a questão dos gêneros se desloca", se generaliza como um "trabalho sobre a linguagem". Podemos levar em conta essa observação para, num primeiro momento, fazer um uso "autorizado" das cartas, considerando-as um documento possível de investigação como pode ser sua ensaística: essa é a postura da crítica, de um modo geral, desde que as primeiras cartas começaram a ser publicadas.

A identificação de algumas particularidades desses textos, no entanto, não precisa ser descartada. O "trabalho de linguagem", o reconhecimento das cartas como documentos específicos, com seu próprio discurso, pode resultar no reconhecimento e na visão do trabalho do autor, a partir de uma perspectiva reduzida - mas em uma escala que se alterna entre a expressão pessoal, juntamente com as demonstrações de afeto, dúvidas e regozijo em relação aos amigos, e a organização de suas próprias reflexões estéticas e decisões daí decorrentes. Lidas em sua singularização, nos obrigam, portanto, a observá-las pelo trajeto das descobertas ali reveladas e sua temática literária e moderna, mas também por sua construção como um texto cujas regras de destinação reúnem seus aspectos mais pragmáticos - é, afinal, uma carta - aos da construção de seu discurso com seus dispositivos próprios de "endereçamento", sua particular "ficção contratual".

E como isso se dá? É indiscutível, para um texto dessa natureza, não só a certeza da existência do leitor, mas especificamente de "um" leitor, ao menos em seu primeiro momento de existência.

E é interessante ainda conjecturar que, originalmente, a carta teria um único destinatário, mas que esse multiplica-se indefinidamente a partir do momento em que ela é publicada, ou seja, num trajeto que vai do singular ao plural, do privado para o público. A crítica talvez possa se isentar, de alguma forma, da culpa dessa propagação "indevida", considerando que as quadrinhas já "autorizam" de algum modo a traição 
que a publicação das cartas efetiva: as cartas foram originalmente escritas para um destinatário, mas sua publicação "trai" esse primeiro contrato, e elas são lidas por muitas pessoas. As quadrinhas brincam previamente com isso, pois são escritas para divertir o destinatário final, mas dependem da leitura - e da compreensão - do "carteiro" para que cheguem até ele: e essa é, portanto, a primeira "traição" do texto, a primeira "brincadeira" do cabotino.

E, não podemos esquecer: pouco mais de meio século depois, o conjunto de suas cartas é completamente "aberto" ao público. Para quais destinatários?

\section{Referências}

ANDRADE, Mário de. Poesias Completas. São Paulo: Itatiaia; Edusp, 1987.

BANDEIRA, Manuel. O centenário de Stéphane Mallarmé. In:

Seleta de prosa. Rio de Janeiro: Nova Fronteira, 1997. p. 503-517.

BANDEIRA, Manuel. Viola de bolso. In: de Janeiro: Nova Fronteira, 1997. p. 166-167.

. Seleta de prosa. Rio

DERRIDA, Jacques. La carte postale: de Socrate à Freud et au-delà. Paris: Flammarion, 1980.

FRIEDRICH, Hugo. Estrutura da lírica moderna. São Paulo: Duas Cidades, 1991.

KAUFMANN, Vincent. Le livre et ses adresses. Paris: Méridiens Klincksieck, 1986.

LACAN, Jacques. O eu e o outro. In: _. O seminário: livro 1: os escritos técnicos de Freud. Tradução de Betty Milan. Rio de Janeiro: Jorge Zahar Editor, 1979.

MALLARMÉ, Stéphane. A ação restrita In: . Divagações. Tradução de Fernando Scheibe. Florianópolis: Editora UFSC, 2010. p. 169-174.

MALLARMÉ, Stéphane. Correspondance I'épistolaire: 1862-1871. Paris: Gallimard, 1959. 
MALLARMÉ, Stéphane. Correspondance: compléments et suppléments. Oxford/UK: University of Oxford, 1998.

MALLARMÉ, Stéphane. Oeuvres complètes. Paris: Gallimard, 1998. v.1. MALLARMÉ, Stéphane. Oeuvres complètes. Paris: Gallimard, 2003. v.2. NORDAU, Max. Dégénérescence. Tradução de Auguste Dietrich. Paris: Félix Alcan Éditeur, 1894. v.2

ROSENFELD, Anatol. Mário e o cabotinismo. In: Texto/ Contexto I. São Paulo: Perspectiva, 1996.

SCHERER, Jacques. Le “Livre” de Mallarmé. Paris: Gallimard, 1977.

Recebido em: 26 de abril de 2018. Aprovado em: 14 de agosto de 2018. 